Peer review: This article has been subject to a double blind peer review process

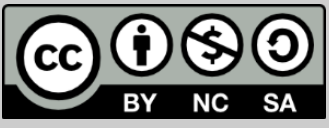

(C) Copyright: The Authors. This article is issued under the terms of the Creative Commons Attribution NonCommercial Share Alike License, which permits use and redistribution of the work provided that the original author and source are credited, the work is not used for commercial purposes and that any derivative works are made available under the same license terms.

\section{Hamlet, Performance and Chaotic Cultural Networks}

\section{Emil Rybczak*}

Department of English, University of Warwick, Coventry UK

*Correspondence: e.rybczak@warwick.ac.uk

\begin{abstract}
Since the 1960s, chaos theory has become an important but controversial tool used by scientists and mathematicians to describe physical or theoretical systems or networks. It explains how the simple can generate the complex. Its central tenets can also provide an alternative language and means of literary interpretation. This article will explore how the principles of chaos theory can be used to close read and systematise various aspects of the language and performance of Shakespeare. The argument is built upon an analysis of 'Hamlet', in an effort to understand the play and its reproduction as the evolution of interconnected complex networks. Various aspects of the text will be discussed, including its language, structural and character patterning, and its reproduction through performance and cinematic adaptation. Each of these topics, and the characters, devices or ideas they discuss, constitute nodes of the complex network of 'Hamlet' as both text and idea.
\end{abstract}

Responding to the cultural analysis of other scholars, this article uses 'Hamlet' as an ideal example of how the appropriation of scientific language can defamiliarise a particular literary or dramatic artefact. This allows fresh interpretation and understanding of its location within the broader networks of theatre and culture. I suggest the possibilities of close reading literary works through the lens of chaos and suggest how they might be applied and developed in conjunction with other texts, media or performances.

Keywords: Chaos theory; performance; network; Shakespeare; Hamlet; theatre

\section{Text as process}

Barnardo: Who's there?

Francisco: Nay answer me. Stand and unfold yourself. (I.i.1-2)

Hamlet begins with a challenge and a question, which epitomises both the play itself and the history of its critical and performance reception. A particular question that has been asked throughout human history is how 
complex structures emerge from more simple ones. Although we cannot justify the spontaneous appearance of being from non-being, we have devised scientific explanations for the processes that develop and connect the world we see around us. In contrast to the degenerative tendency or time-dependent entropic increase of the world, as implied by particular and popular interpretations of the second law of thermodynamics, chaos theory allows for the development of complex systems or networks that are greater than the sum of their parts. It attempts to describe the total behaviour of systems rather than dissecting their parts, and to understand states of becoming rather than of being (Gleick: 1998, passim). ${ }^{1}$

During the last fifty years, chaos theory has developed across technical disciplines, such as mathematics, meteorology, population studies and economics. It has since been appropriated most extensively by the social sciences, a process theorised in Abbott's Chaos of Disciplines (2001), Brady's 'Chaos Theory' (1990), Smith and Higgins' 'Postmodernism and Popularisation' (2003) and Newell's 'Theory of Interdisciplinary Studies' (2001). It has also been used by literary scholars whose work can be divided into two fields of enquiry. The first, exemplified by Hayles (1989; 1990), uses chaos theory as a means of thinking through social systems, with texts as the primary evidence. In this tradition Paulson characterises chaos as 'a perturbation or source of variety in the circulation and production of discourses and ideas' (Paulson, 1988: ix). The second strand of investigation, which informs this article more directly, is exemplified in the work of Hawkins (1995), who uses chaos theory as an analytic framework for understanding texts. I have been particularly careful to avoid suggesting that chaos theory can be used as a metaphor given the extensive problematisation of this by Kellert (Kellert, 2008: 103-120). It is instead, a means of looking or choice of perspective. Many of the authors I criticise build their arguments on unsteady ground by extrapolating chaos as metaphor for chaotic sociological theory. This is particularly evident in Demastes' Theatre of Chaos (1998).

The work of literary scholars appropriating chaos has frequently understood itself, or been understood, as interdisciplinary. This has led a number of scientists, particularly Alan Sokal and Jean Bricmont, to criticise the misuse and abuse of technical terms and concepts deriving from chaos theory (Sokal and Bricmont: 1998, 134-46). In this article, my first aim is to prove that such criticism need not preclude using chaos theory for

\footnotetext{
${ }^{1}$ For my understanding of the science of chaos theory I am indebted to Gleick's Chaos (1999). Further technical exposition of chaos theory for the non-specialist is available in Crutchfield, Doyne Farmer, Packard and Shaw's 'Chaos' or Feldman's Chaos and Fractals (2012). For those more interested in the generation of information and complexity, a different though historically connected field, Prigogine and Stengers' Order out of Chaos (1985) is indispensable.
} 
textual analysis. I rather demonstrate the necessity of acknowledging such work as firmly based in literary studies, and as a means of re-evaluating literary modes of interpretation rather than discovering direct parallels between the abstract and the human. This is achieved through the close reading of an individual text. My second intention is to show that the chaotic tendencies of Shakespeare's Hamlet and other performance texts are best interpreted within the context of their theatrical or cinematic representation. These performance cultures and their evolution should likewise be understood as possessing chaotic tendencies. My analysis is divided into three sections, each concerned with a particular aspect of Hamlet as chaotic. These are its language, structural and character patterning and performance. The first of these suggests how Shakespeare's text might most fruitfully be analysed using chaos theory. The second section on patterning develops this argument whilst pointing towards my second concern regarding the performance or reproduction of texts as displaying chaotic tendencies. The third explores more fully the medium of performance as chaotic and provides examples from the history of Hamlet on stage and screen in support of this.

In rehabilitating chaos theory within literary studies, it is essential to recognise that there are methodological problems that have emerged en masse in this particular mode of reading. There is a tendency, as with all emergent fields, to read texts distantly and theoretically. In so doing, scholars use the principles of chaos theory as directly analogous to literary form, although this is usually unsupportable by close reference to all but a minority of texts. This is apparent in Eoyang's 'Chaos Misread' (1989), Porush's 'Literature as Dissipative Structure' (1992) and Hayles' 'Chaos as Orderly Disorder' and Chaos Bound (1989; 1990). Although Hayles acknowledges the difference between literary and scientific fields this does not correlate with their conflation within the body of her argument (Hayles, 1990: 292).

According to some scholars, such as Sokal and Bricmont, chaos theory is a technical field which, whilst broadly applicable in many contexts, cannot support the wholesale application of its ideas to a humanities subject (Sokal and Bricmont, 1998: 1-17). The theory is useful to literary scholars, but only so long as it is understood as a means of exploring literary construction and dissemination and not as an actual mode of being. A second methodological misapprehension is that chaotic readings are only applicable to those texts that are self-consciously postmodern. The familiarity of authors of postmodern plays, such as Tom Stoppard, with the cultural paradigm from which chaos emerged, can facilitate a direct relationship between their work and chaos. Yet this narrowing of focus misses the power of chaos theory for discussing all manner of texts written long before the theory itself was developed. By considering broad cultural 
systems and postmodern texts as the only ones susceptible to analysis through the chaos model, influential scholars such as Katherine Hayles assume a positivistic interpretation of history and the history of ideas, and suggest that current texts are more complex or self-aware than historical ones. This, however, fails to do credit to the sophisticated understanding that our forebears had of this world, albeit expressed in language that is no longer our own.

One scholar who recognises and avoids both of these pitfalls is Harriet Hawkins in her book Strange Attractors (1995). ${ }^{2}$ In her analysis of Milton's Paradise Lost, which she views as a chaotic text with a chaotic history, Hawkins conceives of chaos as a literary device, rather than theoretical framework. Her ultimate interest is in the chaotic networks both within and between texts. This article builds upon Hawkins's interpretation of chaotic networks, but will explore Hamlet in relation to text and performance, rather than text and literary influence. Hawkins has already suggested Hamlet's potential for analysis:

Probably no play by Shakespeare has more complex dynamics, or has internationally communicated such richness of emotional and intellectual impact as the mirror held up to nature in Hamlet. [...] one-strand, linear interpretations come as single spies on a play simultaneously dealing [...] with battalions of chaotically interacting conflicts and boomeranging schemes.

(Hawkins, 1995: 118-19)

That the inter-discipline of chaos has become popular during the ascendancy of postmodernism suggests a renewed desire to find order in the world and view it as a coherent whole. Its hopeful philosophy has ensured its dissemination in popular culture, either discussed explicitly or as a structuring principle. This is exemplified in Stoppard's Arcadia and in the novel and film adaptation of Michael Crichton's Jurassic Park. Using chaos theory as a means of textual analysis furthermore provides a structural correlative to the angst of decentred and disassociated agency. It provides a new language to express the interconnectedness of literary form and, as I characterise it, the holistic craft of the author. Thus my work, in similarity to that of Hawkins, is aimed particularly at students of literature.

This article reads Hamlet and its performance as a series of complex networks. This play is an ideal subject for inquiry, due to its metatheatricality, or concern with its own form, and its dominant position

\footnotetext{
${ }^{2}$ Analysis along similar lines is also undertaken by Demastes in 'Re-Inspecting the Crack in the Chimney' (1994).
} 
within the cultural field. Its consciousness of, and references to, the medium of performance make explicit the networks of reciprocal influence in which the playwright, play, directors, actors and audience are involved. I refer to specific performances since the written text is characterised as a generative function or idea, its production and reproduction constituting its ongoing development. Although Hamlet was written as a play, it is often encountered in its many cinematic adaptations. Although there are significant distinctions between the mediums of film and theatre, the ephemeral nature of the theatrical encounter makes particular production choices less directly recoverable. I therefore focus on film in my performance examples, although maintain that the structures of influence with which I am concerned are also tenable in the theatrical form. As an audience member's understanding of Shakespeare's text is influenced by a theatrical performance, so a viewer's relationship with that text is augmented by a filmic encounter. A stage production develops throughout its run, and is influenced by initial criticism and audience reception.

It is widely accepted that Shakespeare's texts, like the majority of early modern plays performed on public stages, were created and developed in conjunction with performance. Throughout the seventeenth and eighteenth centuries quarto and octavo title pages frequently advertised their status 'As it is now played [...]'. Although the text and scenography of a film are fixed in its final form, the meaning communicated is dependent on the particular vagaries and preconceptions of each viewer's encounter with the work. Thus chaotic systems still operate between the work produced and the work perceived. This in turn affects later productions, both theatrical and cinematic. Both forms operate within their own systems of historical development, but together participate in the evolution of the text as cultural artefact.

Hamlet is well-known and influential, exhibiting poetic and theatrical devices and techniques visible in many other works, such as a play within the play that reflects and comments upon the main action. Part of Hamlet's critical allure is its dominant position in discourse, since if we can find new ways to read Hamlet we can find new ways to read anything. Texts such as Hamlet that generate new information with each reading and give rise to conflicting interpretations, constitute complex systems understandable as both the text itself and the text in the context of its reproduction in performance. Complex systems are those whose output becomes their new input, and so have the potential to develop in unforeseen ways. This is a principle particularly applicable to performance. Each production is the textual system repeated with new variables. Sensitive dependence on initial conditions, means that slight variations in input will create widely differing results, and ensures the ongoing diversity of new interpretations and readings. The reflexivity of a metatheatrical text typical of Hamlet and 
integral to most of Shakespeare's works, makes this effect even more pronounced. By working backwards from the text as manifested in performance, the complex patterns that Shakespeare deploys emerge as coherent. The reading a viewer or audience member takes of a particular interpretation might serve as one section of a phase space diagram. Such diagrams record the progress of three or more variables generated by a nonlinear equation to show the possible states of a particular system as it repeats non-identically. The representation of chaotic or complex systems can never be complete as the variety of output is infinite, albeit constrained within certain parameters. The pattern produced within these parameters distinguishes it from a truly random system.

It has been suggested that 'if chaos theory gives us a more accurate picture of the physical world, chaos theory would give us a more accurate picture of the language that (re)produces that world' (Boon, 1997: 68). The chaotic processes that govern many physical systems, such as fluid dynamics, create eddies within eddies, nesting systems, attractors or ideas within each other. The popular significance and cyclical reproduction of Hamlet, guarantees it a special place in the cultural matrix, although the same characters and situations are presented and interpreted differently with each performance-the same, yet not the same. Since their lives are structured by the author's text, the characters' deaths are preordained. Although actors will interpret a part, they cannot structurally alter the part they have agreed to play. In committing fully to the representation of a character, actors must furthermore invest part of their self in the character they are portraying. This familiar concept manifests the properties of a strange attractor with its dis/similar iterations. An attractor, frequently visualised using a phase space diagram, constitutes the values or state to which a system will evolve. A strange attractor is normally an attractor manifesting chaotic dynamics, and therefore displaying a fractal structure. This is due to the repeating, but non-identical course of action through which the system it models will cycle, and the pattern to which it will tend. It is globally stable or predictable but locally unstable or unpredictable.

The themes and characters of Hamlet represent the various parts of the strange attractor cycle (of Hamlet as play and as idea) into which productions and actors are drawn. The play works as a strange attractor in its ongoing reproduction, and permeation of other works. Although the superstructures of reception alter over time, the generative equation - the text itself-will continue to manifest shapes that are different in specifics rather than kind. Whilst the Elizabethan text(s) of Hamlet are a complex network of linguistic signifiers created by Shakespeare and his mediators, they are simultaneously the nonlinear equation that ensures the ongoing reinvention and social reintegration of Hamlet and its industry. The following analysis uses the language, patterning and performance of 
Hamlet to explain more particularly how chaos theory might be used in the close reading of a text, its reproduction and evolution, with particular reference to performance.

\section{Language}

In fractal geometry, nonlinear functions or equations are used to generate shapes radically different from those of Euclidean geometry. The building blocks of Euclidean geometry are what we studied at school: circles and squares drawn with rulers and compasses. Fractal geometry was developed by Benoit Mandelbrot and its name derives from fractus, or broken-it is not coincidental that fractal also sounds like fractional. Fractal geometry is the study of those strange or uncanny shapes that defy traditional classification: a fern leaf is fractal. Although these shapes may at first appear irregular, there is order in this complexity, not least in their self-similarity across scales. When a nonlinear function is iterated (repeated with each output becoming the new input) to develop a fractal shape, the equation stretches and folds the curve generated. This has the potential for infinite complexity. Each increase in precision (number of iterations), or level of magnification (viewing the curve generated), reveals new details, which echo without reproducing each other. The exponential increase of a fractal border's complexity facilitates its infinite length, whilst it will still contain a finite area. The regressive detail of these boundaries means that we cannot establish their definite position, only the probability of whether a certain point of whatever exactitude lies within or outside them. Although fractal geometry is only one of several fields to display such properties, occurring as they do across the discipline of chaos, its visible form provides a workable and arresting analogy to the in/adequacy of language for definite expression, particularly as it is deployed in Hamlet. The differences and misunderstandings in what we mean when we speak are problematic but, as Shakespeare suggests, not hopeless.

Quibbles are a form of word play, in both dialogue and monologue, which are a recognisable feature of Shakespeare's art. They nibble at, destabilise and reframe semantic signification, as in the below exchange:

$\begin{array}{ll}\begin{array}{l}\text { Claudius: } \\ \text { son- }\end{array} & \text { But now my cousin Hamlet, and my } \\ \text { Hamlet: } & \begin{array}{l}\text { (Aside) A little more than kin, and less } \\ \text { than kind. }\end{array} \\ \text { Claudius: } & \begin{array}{l}\text { How is it that the clouds still hang on } \\ \text { you? }\end{array} \\ & \text { Not so my lord, I am too much }\end{array}$


I'th'sun. (I.ii.65)

When Shakespeare's characters quibble they iterate their initial statement or point of contact into a complex negotiation, questioning the premises and precision of their interlocutor's proposition. The nature of such linguistic play refocuses the boundary between the characters, where language both connects and separates them. Such instability at the borders of language means that although it is a primary form of social interaction, it can also form a conceptual prison, which locks the individual in their own web of meaning. As Wittgenstein argues, 'the essential thing about private experience is really not that each person possesses his own exemplar, but that nobody knows whether other people also have this or something else' (Wittgenstein, 1968: para. 272). In the melancholic interpretation of Laurence Olivier, Hamlet's closest human contact is with the Jester Yorick's skull, caressing it more tenderly than his betrothed Ophelia (1948). Shakespeare's quibbles are both a lament for individual alienation and an attempt to negotiate the linguistic border between the self and the other. As previously stated, the boundary generated by a chaotic function marks the point at which the consequences of its iteration are unknown. The boundary is creative since its latent complexity has the potential for infinite investigation.

Like Hamlet, a fractal shape is definable but not totally comprehensible. The equation that generates such a shape is best understood as a process. Likewise Hamlet is always in a state of becoming since he cannot be completely demarcated, only imagined to a greater or lesser degree. If language, however skilfully devised or rendered, struggles to reproduce completely the complexity of the emotions or ideas it seeks to represent then, like fractal geometry, it is an ongoing process of approaching meaning. Part of Hamlet's frustration, and the motivation for his introspection, must derive from his inability to find sufficiency in language to fully communicate his internal logic. The complexity of the border between him and the audience is developed by Shakespeare through his use of metaphoric language, forever promising more meaning than can be apprehended at any given juncture: 'But I have that within which passes show $-\mid$ These but the trappings and the suits of woe' (I.ii.85-6).

Although Hamlet's speech includes more metaphors and extended metaphors (understood by Elizabethans as 'conceits') than any other character in Hamlet, it is a rhetorical technique used throughout the Shakespearean canon. The metaphor seeks to develop, through iteration and investigation, an idea that denies full expression in its most obvious terms. The potential insufficiency of such conceits is best explained by Hamlet in his response to the scheming of supposed friends Rosencrantz and Guildenstern: 
Why look you how unworthy a thing you make of me. You would play upon me, you would seem to know my stops, you would pluck out the heart of my mystery, you would sound me from my lowest note to the top of my compass - and there is such music, excellent voice, in this little organ, yet cannot you make it speak. 'Sblood, do you think I am easier to be played on than a pipe? Call me what instrument you will, though you can fret me, you cannot play upon me. (III.ii.329-36)

When the ideas communicated by the metaphor are sufficiently complex, then, even in the hands of Shakespeare, language is sometimes insufficient to express the idea fully and only hints at the poet's true meaning. It offers the representation of a thought or feeling so that it can be seen more clearly, although it is an imperfect reproduction rather than the thing itself. This is why the character of Hamlet offers infinite opportunities for conflicting interpretations, because his true thoughts and motives, particularly as they have developed through centuries of interpretation, cannot be fully expressed in the language Shakespeare affords him. Shakespeare's art is to offer the most developed language and yet still to suggest more than can be said. No interpretation is final, and each brings to mind all the others that we may have seen or read, so that the silent short Le Duel d'Hamlet overflows with an excess of signification largely due to its enigmatic form (Howard, 2007: 98-136).

When dialogue is offered willingly by two parties in a discussion, each contributing amply and questioning the meaning of their interlocutor, a fractal boundary is developed within the language they share. Shakespeare's first and second gravediggers, for example, negotiate meaning through banter, and Hamlet finds an unexpectedly sympathetic spirit in the first gravedigger. Surrounded by death the gravedigger is able to treat his work with a levity that complements Hamlet's melancholia:

Hamlet: Whose grave's this sirrah?

Clown: Mine sir.

$$
[\ldots]
$$

Hamlet: I think it be thine indeed, for thou liest in't.

Clown: You lie out on't sir, and therefore 'tis not yours. For my part, I do not lie in't, yet it is mine.

Hamlet: Thou dost lie in't, to be in't and say 'tis thine.

'Tis for the dead, not for the quick, and therefore thou liest.

Clown: 'Tis a quick lie sir, 'twill away again from me to 
you.

Hamlet: What man dost thou dig it for?

Clown: For no man sir.

Hamlet: What woman then?

Clown: For none neither.

Hamlet: Who is to be buried in't?

Clown: One that was a woman sir, but rest her soul she's dead.

Hamlet: How absolute the knave is! (V.i.99-115)

The tragedy in this scene is that the fractal approach to the truth of the matter, the hedging around any definite answer, serves only to delay the terrible realisation that the grave is Ophelia's. The fuzziness of the quibble can obscure or delay meaning as well as clarify it.

Hamlet tries to engage with almost everybody, inviting them to negotiate with him linguistically, but these offers of dialogue are frequently rebuffed. In a discussion with the royal adviser Polonius, Hamlet cannot precipitate the conversation he desires (II.ii.168-212). Although each of Hamlet's lines builds upon and reinvents that which preceded it, Polonius refuses to engage with Hamlet's invitations for him to question their semantic boundary. Hamlet's speech is complex and ambiguous, but Polonius returns only the simplest of statements or questions. This is what leads Hamlet to end their conversation with the repetition of 'except my life' in protest to Polonius' refusal to play the language game (II.ii.210). Because Polonius has already decided that Hamlet is mad, the two characters become incompatible, despite Polonius' stated sympathy: 'And truly, in my youth I suffered much extremity for love, very near this' (II.ii.186-7). Polonius ensures intellectual distance from Hamlet by only quibbling with himself. In Polonius' first extended scene, where he offers advice to his son Laertes before his departure for Wittenberg, every statement has a qualification, every suggestion a development:

Beware

Of entrance to a quarrel, but being in,

Bear't that th'opposèd may beware of thee.

Give every man thy ear, but few thy voice;

Take each man's censure, but reserve thy judgment.

Costly thy habit as thy purse can buy, 
But not expressed in fancy: rich, not gaudy. (I.iii.65-71)

Whenever characters defer either to Hamlet's madness, as Polonius does in Act Two Scene Two, Hamlet's alienation and separation are increased. This is suggested in his frustration at the foppish courtier Osric and the courtly world he represents:

A did comply with his dug before a sucked it. Thus has he, and many more of the same bevy that I know the drossy age dotes on, only got the tune of the time and outward habit of encounter, a kind of yesty collection, which carries them through and through the most fanned and winnowed opinions; and do but blow them to their trial, the bubbles are out. (V.ii.165-70)

Such dissatisfaction with the world leads to the sublimation of Hamlet's dialogue to create fractal borders within his monologues. The dialogic nature of these soliloquies offer the audience an insight into Hamlet's internal debate, more usually played out between the self and the other. This is apparent in the 'To be, or not to be [...]' speech (III.i.56-90). His deferral of choice and positive action, as explored in his monologues, maintains and develops his possibilities. His ultimate unknowability, facilitated by the demarcating rather than defining tendencies of his language, allows his thoughts and acts to be interpreted as displaying 'higher and higher levels of organization and complexity' (Davies, 1987: 119).

The language of Hamlet is the play's most basic expression, and it is Shakespeare's talent for ambiguity that makes it particularly chaotic. Linguistic play forms a network marking the boundaries between self and other, and displays similar properties to the borders of fractal geometry. The exceptional complexity and impenetrability of Hamlet's character derives from his sublimation of the fractal boundary, usually externalised, within his own consciousness as expressed in his soliloquies. Although the networks that are more often wrought between the play's characters find their most complex manifestation within Hamlet himself, the fractal nature of language is visible across Shakespeare's plays, and in the works of many other authors.

\section{Patterning of Structure and Character}

Shakespeare's language displays chaotic properties at the micro-level, in his use of quibble and conceit, dialogue and its sublimation. The patterning he deploys through characters and structure can also be analysed in the language of chaos. I shall again use the analogy of fractals, and their selfsimilarity across scales, to draw attention to the similarities between 
protagonists, and between the protagonists and players. The same actions, such as death by poison, are reproduced many times within a single performance. The characters concerned are also trapped in specific roles and patterns of action dictated by their social or familial duties and status, and their positioning within the revenge-tragedy plot. Their actions have far greater significance for the network of the play and of its cultural position than can be known by the characters themselves.

We have seen the complexity that is developed at a fractal linguistic boundary. Another important property of fractals is their self-similarity across scales. This means that similar patterns are reproduced at all levels of magnification. Although a fractal will appear different when viewed from different perspectives, it will always conform to the same fractional dimension. A fractional dimension records the extent to which a fractal transgresses the boundaries between conventional geometric planes, essentially denoting a degree of irregularity. Within Hamlet there are similarities and echoes between greater and lesser characters, and between each character and their forebears. This is significant not only within the text, but also across its reproduction.

Hamlet's consciousness of his similarity to Old Hamlet wracks Hamlet with a dual responsibility to be both different and the same as his father. His now regnant uncle Claudius tells Hamlet that 'your father lost a father, I That father lost, lost his' (I.ii.89-90). In Franco Zeffirelli's film (1990) these words find particular potency when Hamlet gives the 'To be, or not to be' speech in his ancestors' tomb. With skeletons lying open to view in this scene, Hamlet cannot forget his patrilineal duty. There is a parallel scene in Svend Gade's adaptation (1921) when this female Hamlet mourns at her father's tomb, its low vault and barred windows imprisoning her in a net of light. Yet stripped of political authority no Hamlet has the same resources for action as were available to his father, although he will likewise die by poison. In David Farr's Royal Shakespeare Company production (2013), fencing and its apparel provide a hereditary link between Hamlet and his father. Old Hamlet's ghost gives Hamlet his mask in lieu of his crown. The next time Hamlet appears he is sporting this mask and frequently carries it throughout the remainder of the play, wearing it in his duel with Laertes (the son of Polonius). When he dons his own fencing clothes Hamlet bears a distinct visual resemblance to his father. Masked, he goes so far as to become his father avenging himself. We see here not only the echoes between characters suggestive of self-similarity across scales, but also some form of strange attractor, acting upon and controlling the actions of the father and son and assimilating both their individual characters and function within the revenge plot.

Hamlet's responsibilities to his father are complicated by the similarities between Old Hamlet and Claudius. This is particularly apparent when the 
parts are doubled, with two characters played by one actor, as in Gregory Doran's version (2009). ${ }^{3}$ Doubling is a common practice, and was likely used in Shakespeare's theatre. The meaning of identity is reflected and refracted in any attempts to establish discrete fixity:

$$
\begin{array}{ll}
\text { Gertrude: } & \text { Hamlet, thou hast thy father [Claudius] } \\
\text { much offended. } & \\
\text { Hamlet: } & \begin{array}{l}
\text { Mother, you have my father [Hamlet] } \\
\text { much offended. (III.iv.9-10) }
\end{array}
\end{array}
$$

The marriage of Hamlet's mother Gertrude, first to Old Hamlet and then to his brother Claudius, entrenches the connection between these men. There are also similarities between the personalities, situation and actions of Hamlet, Laertes and the Norwegian prince Fortinbras. Each young man echoes and casts new light upon his peers. Hamlet suggests 'by the image of my cause, I see | The portraiture of his [Laertes']' (V.ii.77-8). The coincidence of Hamlet's birth with his father's defeat of Old Fortinbras provides a precedent for the further interweaving of his fate with that of Fortinbras.

These characters all possess high social status and, since Hamlet is a tragedy, it is concerned primarily with the mishaps of its ruling class. It is impossible for Shakespeare's characters to be separated as personalities from the social situation that constructs them. They each have a particular role to fulfil in the drama's plot, and simultaneously possess certain destinies, which are dictated by the genre and groups that the play delineates. Shakespeare's characters are similar types (the Ghost; the King; the Queen; the Friend; the Ingénue) to those in his other tragedies, as well as those of his contemporaries. This was a situation exacerbated by the performance conditions of the Globe, where plays were staged in quick succession by a limited number of actors. Although each of the protagonists in Hamlet is subject to the logic of their tragic fate, the resultant textual constraint is experienced most acutely by Hamlet. Laertes warns Ophelia of Hamlet's responsibilities as a prince: 'His greatness weighed, his will is not his own, | For he himself is subject to his birth' (I.iii.17-8). The responsibilities of nobility are often emphasised in production. The Player King of the play within the play in Farr's production (2013) wore such a massive crown that it pulled him about the stage as he tried to recite his lines.

Although famous for his vacillation, Hamlet does eventually conspire with providence in accepting the fate that his birth and father's ghost have laid

\footnotetext{
${ }^{3}$ This was first performed live at the Royal Shakespeare Company theatre, but I cite the BBC adaptation.
} 
out for him. When he finally comes to terms with the inevitability of his fate, Hamlet's actions acquire a significance that they lacked when he was fighting his destiny. This is a view supported by Demastes, who likewise privileges fate in his discussion of chaos in relation to Hamlet (1998: 14043). The implications that Hamlet's actions have for other characters, and the functioning of the whole action as a network, are revealed in the flattery of Claudius by Hamlet's childhood friend Rosencrantz:

The cess of majesty

Dies not alone, but like a gulf doth draw

What's near it with it. It is a massy wheel

Fixed on the summit of the highest mount,

To whose huge spokes ten thousand lesser things

Are mortised and adjoined, which when it falls,

Each small annexment, petty consequence,

Attends the boisterous ruin. (III.iii.15-22)

The death of Old Hamlet and of Hamlet in his turn, constitute crises in the lives and deaths of the other characters, both influencing their actions whilst also being simultaneously created by them. Ophelia continues to affect events, even after she has retreated into madness: 'Hadst thou thy wits, and didst persuade revenge, | It could not move thus' (IV.v.168-9). In Gade's film adaptation (1921), Hamlet's greatest secret, that she is a woman, is recognised by her best friend Horatio only upon her death. He buries her secret and allows the soldier's funeral to continue. Although everyone is responsible for the play's development, no-one is culpable. Whilst Gade made a significant addition to Shakespeare's text by supplying a particular motivation for Hamlet's unwillingness to act, this cannot alter the course of events laid down by Shakespeare's script. Although the ends of the characters may be unknowable, they are also unalterable. All of the characters work together in the consummation of their collective destiny.

The prime lever in this destiny is Hamlet's revenge of his father's death. Within the plot, the multiple retellings of Old Hamlet's murder reveal it to be a strange attractor to which the son must conform. His murder occurs not only from performance to performance, but also four times in each performance: with the ghost's tale (I.v.1-91), Hamlet's report to Horatio (referred to III.ii.66-7), the dumb show (III.ii.120) and the Mousetrap (III.ii.136-245). In this way, Hamlet also displays fractal properties in the similarities Shakespeare draws between actual characters and those created by the players. Hamlet acknowledges and even demands this analogy: 'I'll have these players | Play something like the murder of my 
father | Before mine uncle' (II.ii.547-9). He does not need the past to be replayed exactly for Claudius to recognise it. A variation on the theme will recall the original crime. Hawkins emphasises the significance of the players in Hamlet:

Thus, in effect, it could be argued that the 'metadramatic' recursions recognized everywhere by his twentiethcentury critics as perhaps the most ubiquitous, if not the most ubiquitous principle of Shakespeare's art, are so close to the tenets of 'self-similarity' in chaos theory as to seem theatrical analogues to them. (Hawkins, 1995: 108)

Each replaying also echoes a past representation, blurring the boundary between action and representation. When Ethan Hawke speaks the above lines from Act Two Scene Two in Michael Almereyda's film (2000), he is watching a video of Laurence Olivier's address to Yorick's skull. He seems to derive his motivation or actions not from his own inspiration, but from the example of previous Hamlets, reconstituting Olivier's 1948 performance. The text of the play ensures repetition, whilst its multiple modes of interpretation facilitate difference. The significance of players and playing therefore extends across time beyond the boundaries of each particular representation.

The reciprocal dynamics of chaos theory describe how its systems are liable to both downward and upward causation. Linkages across various levels of perception ensure that a change in one will simultaneously alter all of the others. ${ }^{4}$ The Mousetrap is a play within the play based on 'The murder of Gonzago' but with added speeches by Hamlet emphasising the similarity of its action to the murder of his father (III.ii). Its performance straddles a boundary between the reproduction of what has happened and the catalytic precipitation of the events described in the dumb show, a silent representation of the forthcoming action that precedes it. It both reproduces and affects. Although the fictitious players are not aware of the consequences of their actions, Hamlet stages the Mousetrap with full knowledge of its potential intervention in the progress of events. It is with this knowledge that Hamlet is a tragic participant in his own demise. Although he may ask the players to perform anything and thus encourage change or progress, he requests a narrative that reflects his own concerns - the murder of his father-and therefore folds the action back on itself. Viewing past events ensures their repetition, and simultaneously prevents the characters from escaping their particular network and

\footnotetext{
${ }^{4}$ This effect is explained well using the examples of Cantor's Set, a mathematical conceit, or the crack of a whip (Hayles, 1990: 156).
} 
engaging with the social, political and intellectual world beyond Elsinore.

Although drawn towards it, Hamlet experiences a conflict with the violent model of revenge, as reported in the Player's first speech, which takes from Homer's Iliad a description of Priam's death at the hands of Pyrrhus (II.ii.426-55). Thus when he sees Claudius at prayer he will not act, because the manner of his father's death necessitates his revenge by poison (III.iii.73-96). The plot functions reflexively since it is Claudius' plot against Hamlet that facilitates his own death by poisoning. The repetition or attraction of poison is ultimately manifested in the deaths of Old Hamlet, Hamlet, the Player King, Claudius, Laertes and Gertrude.

As the play is itself a strange attractor, so are aspects of its plot, their significance growing with varying repetitions. Sensitive dependence on initial conditions eliminates the random, so that "chance" becomes a word denoting only ignorance. It means "determined by some as yet unknown, or unspecified, means"' (Dawkins, 1989: 218). When a linear system is disturbed, its output may be fundamentally altered. When a nonlinear system is disturbed, the robustness of the function, the power of the strange attractor, can ensure its continued operation, even though tiny variations in input can generate massive divergence in output. The process by which a function manipulates its variables amplifies their effect on the system. Old Hamlet's description of poison recalls this process:

The leperous distilment, whose effect

Holds such an enmity with blood of man

That swift as quicksilver it courses through

The natural gates and alleys of the body,

And with a sudden vigour it doth posset

And curd, like eager droppings into milk,

The thin and wholesome blood. (I.v.64-70)

The poison described by the Ghost of Hamlet's father might also apply to the effect that this encounter has on Hamlet. His injunction to 'remember' overruns and permeates Hamlet's entire consciousness. The inevitable consequences of his revenge extend beyond Hamlet and Claudius to consume the other characters of the play. The poison works as a variable input applied to a system, the consequences of which are massive and inevitable.

Yet in a complex network any prediction is impossible, even though the system is deterministic. This is because its infinite complexity derives from sensitive dependence on initial conditions, to an infinite degree of accuracy. The only way to establish behaviour at a given point or scale is 
for the function to be allowed to play out to that degree. By viewing characters as nodes within this network, it is clear that that their fate is preordained but to them unknowable. Any accurate knowledge of the future would cause a paradoxical intersection of the similar periods of their temporal development and cause repetition. With the end of chaos would come the end of creative unknowability. Although subservient to Shakespeare's plot, the characters must nevertheless maintain belief in their own autonomy. 'The combination of audience foreknowledge that things will go wrong [...] with the character's ignorance as to the subsequent course of events has been the prime source of dramatic irony from Greek times to the present. Indeed, deterministic chaos is the rule in art' (Hawkins, 1995: 44). Thus not only does the patterning Shakespeare uses between characters recall the self-similarity of fractals, but their metatheatrical awareness invites us to see beyond the vagaries of an individual interpretation to the recursions and variations that develop across productions and across time.

\section{Performance}

Players are employed to be watched, and their actions find purpose in the knowledge that somebody is watching. The theatre, and now the cinema, are both spaces for viewing, and Shakespeare's Hamlet demonstrates more authorial concern with the effect and power of watching than most plays. The Murder of Gonzago acquires its significance only as it becomes the Mousetrap, watched by the characters of Hamlet. Observation, or knowledge of it, forms and strengthens networks between characters and an audience, which prove integral to the course of events. Gregory Doran maintains a theatrical space in the TV adaptation of his stage production (2009). In the play within the play scene (III.ii) Claudius, Gertrude and the courtiers are arranged upstage, the Player characters perform centre stage, and Hamlet and Ophelia are downstage in the place that should be occupied by an audience. Yet beyond this, there is only darkness, recalling unseen spectators. In Grigori Kozintsev's film (1964), by contrast, the royal party occupy a higher stage than the Players, backed by three archways that reimagine the tiring house or backstage area, similar to the Greek skene, of the Elizabethan theatre. The theatrical representation of Hamlet by the Players is essential for the plot's development. It is not the text that captures the conscience of Claudius, but his understanding of being shown it. Likewise the delivery of soliloquies directly into the camera further implies an audience complicit in events. This is likewise the case when RSC or Globe visitors are acknowledged in asides and direct addresses. These techniques enjoy a strong tradition in Shakespeare on film, and are perhaps more common than in many contemporary stage productions. The BBC Shakespeares of the 1980s, for example, are entirely preoccupied 
with their theatrical heritage.

In Shakespeare's play within the play, Ophelia is interested in Hamlet, Hamlet and Horatio in Claudius, Claudius in the play, and the Player King in his onstage audience; the audience watches them all (III.ii). Each individual gaze alters and develops the meaning of what is being viewed. Furthermore, aware of their situation, the viewed draw the viewers into their network and implicate them in its action. When Hamlet has his most extended interview with Ophelia ('Get thee to a nunnery [...]', III.i.88-143) he will usually register that he is being watched. This influences his behaviour towards her and the course of future events. Laurence Olivier, who looks straight at the hangings behind which the eavesdroppers hide in his 1948 performance, is aware of their presence throughout the scene and so is consistently cold with Ophelia. The multiple levels of the great hall allow this Hamlet to do his own share of watching. In his version of Hamlet Michael Almereyda is particularly concerned with cinema, television and voyeurism (2000). In this interpretation Ophelia is wired in her interview so that Claudius and Polonius can listen in from a distance. In the first half of the scene, Hamlet is tender. It is only when he makes to undress her that a microphone is discovered, and Hamlet asks the whereabouts of her father. The change in tone is enacted as much by Ophelia's grief at the results of her actions, as by Hamlet's anger or disillusionment. The act of watching, or listening, is the direct cause of the failure of their reunion, and is the critical event in Ophelia's alienation from Hamlet and descent into madness.

In this complex network, the act of watching introduces additional factors, which change the terms of the system's development, and thus alter the results from what would have been obtained had the viewing not occurred. ${ }^{5}$ As a self-conscious performance, be it on stage or film, the text of Hamlet incorporates the audience's gaze and thus its meaning is altered. A film will remain the same across multiple screenings, but the audience's response will alter and develop based on any number of cultural factors. Since chaotic properties appear random if viewed discretely, Hamlet can only be fully apprehended when contextualised within its ongoing iteration as a historical cultural artefact. In its final scene the dying hero implores Horatio:

\footnotetext{
5 This suggestion is not to be confused with Heisenberg's uncertainty principle, as applicable to quantum dynamics and represented theatrically in Stoppard's play Hapgood. I use the significance of watching and being watched in a more general and traditional sense. The error of conflating this with the specific tenets of Heisenberg is expounded by Sokal and Bricmont in an extended checklist of common faults in the appropriation of science by other disciplines (1988).
} 
If thou didst ever hold me in thy heart,

Absent thee from felicity awhile,

And in this harsh world draw thy breath in pain

To tell my story. (V.ii.325-8)

In Almereyda's production, we are at this moment shown a montage from Hamlet's perspective of the film's action, implying that this Hamlet reflects the protagonist's view of events.

However, since each occasion of the play's retelling is unique, the injunction to tell Hamlet's story must encompass all possibilities of production. Hamlet dies looking both forward, to his place in posterity, and back, to before the story began, wondering if its events had meaning. Hamlet's words suggest that the plot might be comprehended only by those outside of it:

Our wills and fates do so contrary run

That our devices still are overthrown;

Our thoughts are ours, their ends none of our own.

(III.ii.192-4)

Almereyda moves these lines to form the film's epilogue, with the news anchor Robert MacNeil reading them from an autocue. The fixity of the text is emphasised in conjunction with its impenetrability for those trapped within it. They pass the burden of comprehending the whole beyond the text onto us, the audience. Although the observer affects the development of the complex network, he has more ability to comprehend its totality than the characters within it, physically as well as textually. When imprisoned in a film recording, characters are further disempowered.

Considering the heritage of such a play as Hamlet, there is an uneasy relationship between each generation of its actors. The theatre in particular is an establishment with strong traditions, but there is simultaneously an expectation that each production will do something new, just as each film will be both reassuringly similar to and engagingly different from the last. Audiences expect novelty within the familiar. Although such concerns affect all productions of Hamlet, they are particularly apparent in Sir John Gielgud's (1964) recording of the original stage production in situ. In the 'theatrical trailer' Richard Burton introduces the play by listing important Hamlets of the past: Burbage, Garrick, Kean, Booth, Irving, Barrymore and Gielgud. He explains how most recently 'it has been my privilege to play my interpretation of Hamlet'. Listed as a significant interpreter of the role, Gielgud has now become 
Burton's director. Furthermore, in this new production, Gielgud plays the ghost of Old Hamlet. As his disembodied voice echoes across the stage, boundaries are blurred between input and output, subject and object, last Hamlet and Old Hamlet. When the ghost's shadow looms across the curtains, it provides the correlative to his missing body. Although the interpretations of a previous age can represent an ideal to which to aspire, they also constitute a snare that could doom one to repetition. In this production in particular the missing body of Gielgud (in likeness to the ghost of Old Hamlet) passes the onus of invention from father to son, from old Hamlet to new. Like Hamlet, the new actor of Hamlet must find their own way, whilst simultaneously treading in the footsteps of his father.

Due to the reciprocal and affective feedback of a complex network, no act or node is independent, and each has influence on the others. Thus in Hamlet, as the actions of the son are influenced by the fate of the father, so our vision of the son can alter our vision of the father. As a system's output is altered by a single variable, other variables are attracted to the new rhythm and are altered as they compensate for this change. The parameters of a network are fixed by the text, but each iteration is renegotiated as the system responds to varying inputs. Existing as a part rather than a summation of the idea of Hamlet, each production is governed by that which went before, simultaneously influencing its next embodiment. Thus the theatrical system is nonlinear. All contributory factors are implied in the function of the network thus established. The characters are trapped within the play itself, dependent for their development upon their representation and reception. The actors and contributors to a production are likewise dependent upon the characters and actions they depict, with equal responsibilities and governing expectations. The audience also participate in the development of the work, formulating its future meaning in their understanding of the production.

Since the solution of a chaos-inducing nonlinear equation is dynamic it is, whilst real, inexpressible in any manner other than the system implied. This argument again applies to fractal geometry. The disparate points that are drawn and connected, are all subservient to the single nonlinear equation that generates them. The more points that are plotted, the more a distinct map or web of connections will appear. These connections were there all along, but do not reveal themselves until they are looked for. This looking is itself a variable in the system, altering and developing that which it views. To seek definitive resolution to a text is like applying the principles of a solvable equation to one which is unsolvable. To answer definitively a play's questions or textual equation creates a freeze-frame of its meaning at a particular historical-cultural moment, reducing the dynamic to the static. Any critical analysis is a form of information generated by the 
iterative process, and in seeking to explain a part of the network, may end up contributing to its evolution. The only adequate means of understanding Hamlet is through its ongoing development in real time, its changing forms of representation.

\section{A means to an end}

The language of chaos theory might be used to describe a variety of Shakespeare's plays. A Midsummer Night's Dream examines a chaotic network at different levels of magnification, and the History Plays record its long term development. The Tempest takes a small network and presents it coherently. My analysis of Hamlet is necessarily incomplete, straddling as it does various periods, forms of representation and significance. However, understanding the text as an evolutionary process makes incompleteness a critical necessity. To this end, the use of language or ideas borrowed from science, as an interpretative lens rather than theoretical framework, is a valuable resource for students of literature in providing new ways to think about old texts.

I have endeavoured to demonstrate the power of chaos theory as a tool not only for theorising, but also for close reading. Furthermore, I have suggested ways in which the performance-audience dynamic might be conceptualised as a complex system. In the pursuit of clarity I have broken my argument down into text, patterning, and performance, but the interaction of these fields and excess of meaning in Shakespeare's plays make their formal separation impossible. One aspect of a text can find a variety of parallels. Likewise a single parallel can apply to a greater or lesser quantity of the text. Any adequate assessment of a complex network requires approaching the whole rather than the part. The interlacing of cultural artefacts and fields problematises this ideal and necessitates the artificial creation of boundaries around the text(s) under discussion.

Nevertheless, and with due caution, the language of chaos theory is an exciting and powerful tool to be embraced by literary scholars. Such new corpora of descriptive possibilities usually come hand in hand with a theoretical campaign, yet by embracing an alternative language, space is made for the specifically literary and theatrical reassessment of some of the most familiar of texts. My use of chaos theory to consider the language, patterning, and performance of Hamlet, and of the dynamic nature of theatre and cinema more generally, has sought to prove this. 


\section{Acknowledgements}

I would like to thank Barbara Ravelhofer under whose supervision the ideas contained in this article were initially developed, and the editors of Exchanges whose extensive queries and suggestions have helped to develop and clarify my argument.

\section{Textual Bibliography}

Abbott, Andrew (2001), Chaos of Disciplines, Chicago: University of Chicago Press

Boon, Kevin Alexander (1997), Chaos Theory and the Interpretation of Literary Texts: The Case of Kurt Vonnegut, Lewiston, NY: Edwin Mellen Press

Brady, Patrick (1990), 'Chaos Theory, Control Theory, and Literary Theory or: A Story of Three Butterflies', Literature and Science, 20 (4), 65-79

Crutchfield, James P., Farmer, J. Doyne, Packard, Norman H. and Shaw, Robert S. (1986), 'Chaos', Scientific American, 255 (6), 38-49

Davies, Paul (1987), The Cosmic Blueprint, London: Unwin

Dawkins, Richard (1989), The Selfish Gene, Oxford: Oxford University Press

Demastes, William W. (1994), 'Re-Inspecting the Crack in the Chimney: Chaos Theory from Ibsen to Stoppard', New Theatre Quarterly, 10 (39), 242-54

--- (1998), Theatre of Chaos: Beyond Absurdism, Into Orderly Disorder, Cambridge: Cambridge University Press

Eoyang, Eugene (1989), 'Chaos Misread: Or, There's Wanton in My Soup!', Comparative Literature Studies, 26 (3), 271-84

Feldman, David P. (2012), Chaos and Fractals: An Elementary Introduction, Oxford: Oxford University Press

Gleick, James (1998), Chaos: Making a New Science, London: Heinemann Hawkins, Harriett (1995), Strange Attractors: Literature, Culture and Chaos Theory, New York; London: Prentice Hall

Hayles, N. Katherine (1989), 'Chaos as Orderly Disorder: Shifting Ground in Contemporary Literature and Science', New Literary History, 20 (2), 30522

--- (1990), Chaos Bound: Orderly Disorder in Contemporary Literature and Science, Ithaca, NY: Cornell University Press 
Howard, Tony (2007), Women as Hamlet: Performance and Interpretation in Theatre, Film and Fiction, Cambridge: Cambridge University Press

Kellert, Stephen H. (2008), Borrowed Knowledge: Chaos Theory and the Challenge of Learning Across Disciplines, London: University of Chicago Press

Newell, William H. (2001), 'A Theory of Interdisciplinary Studies', Issues in Integrative Studies, 19, 1-25

Paulson, William R. (1988), The Noise of Culture: Literary Texts in a World of Information, London: Cornell University Press

Porush, David (1992), 'Literature as Dissipative Structure: Prigogine's Theory and the Postmodern "Chaos" Machine', in Greeberg, Mark L. and Schachterle, Lance (eds.), Literature and Technology, Bethlehem, PA: Lehigh University Press, 275-306

Prigogine, Ilya, and Stengers, Isabelle (1985), Order Out of Chaos: Man's New Dialogue With Nature, London: Flamingo

Shakespeare, William (2003), Hamlet: Prince of Denmark, ed. Edwards, Philip, Cambridge: Cambridge University Press

Smith, W., and Higgins, M. (2003), 'Postmodernism and Popularisation: The Cultural Life of Chaos Theory', Culture and Organization, 9 (2), 93-104

Sokal, Alan, and Bricmont, Jean (1998), Fashionable Nonsense: Postmodern Intellectuals' Abuse of Science, New York: Picador

Wittgenstein, Ludwig (1968), Philosophical Investigations, trans. Anscombe, G. E. M., Oxford: Blackwell

\section{Performances Cited}

Almereyda, Michael (2000), Hamlet, [DVD], USA: double A Films

Brannagh, Kenneth (1996), Hamlet, [DVD], USA: Warner Home Video

Doran, Gregory (2009), Hamlet, [DVD], UK; Japan; USA: BBC

Gade, Svend (1921), Hamlet, [online], Germany: Art-Film GmbH, available from

<http://www.youtube.com/watch?v=amib242_IL8\&list=PL3BB9F1B089C

539DA> [17 April 2013]

Gielgud, Sir John (1964), Hamlet, [DVD], USA: Theatrofilm

Kozintsev, Grigori (1964), Hamlet, [DVD], Soviet Union: Lenfilm

Olivier, Laurence (1948), Hamlet, [DVD], UK: Two Cities Films 
Maurice, Clement (1900), Le Duel d'Hamlet, [online], France: PhonoCinema-Theatre, available from

<https://www.youtube.com/watch?v=Mp_v_dP8s-8> [21 September 2015]

Shakespeare, William (2013), Hamlet, Directed by David Farr, Royal Shakespeare Company, Royal Shakespeare Theatre, Stratford-UponAvon, [30 March 2013]

Zeffirelli, Franco (1990), Hamlet, [DVD], USA; UK; France: Canal+; Caralco Pictures; Icon Entertainment International; Marquis; Nelson Entertainment; Sovereign Pictures; Warner Bros.

To cite this article:

Rybczak. (2015). 'Hamlet, Performance and Chaotic Cultural Networks'. Exchanges: The Warwick Research Journal, 3(1), 41-64. Retrieved from http://exchanges.warwick.ac.uk/index.php/exchanges/article/view/71 